\title{
ОТЕЧЕСТВЕННАЯ ИСТОРИЯ:
}

люДИ, СОБЫТИЯ, ФАКТЫ

DOI: $10.47026 / 2712-9454-2020-1-3-5-13$

УДК 94(470)

ББК 63.3

В.В. АВДАНИН

\section{СТО ЛЕТ ЭЛЕКТРИФИКАЦИИ: ИСТОРИЧЕСКИЙ ОПЫТ И СОВРЕМЕННЫЕ ВЫЗОВЫ}

Ключевые слова: план ГОЭЛРО, Генеральный план электрификации СССР, энергосистема Средней Волги, Чебоксарская ГЭС, Чувашия.

В статье на основе принципов историзма и объективного анализа рассмотрены особенности и проблемы реализации двух государственных планов электрификации: плана ГОЭЛРО, принятого 100 лет назад, в рамках которого началось строительство местных электростанций в районах Среднего Поволжья, и Генерального плана электрификации СССР, утвержденного в 1932 г., который заложил основные решения по коренному переустройству промышленности и сельского хозяйства региона на основе использования источников гидроэлектроэнергии, сооружаемых на Волге. В этой связи историко-сравнительный метод позволил выделить основные этапы создания и развития энергосистемы Чувашской республики, которая с середины 1950-х г2. выполняла роль центрального звена в единой энергетической системе страны. Идея создания энергетических узлов Волжского каскада, которые в дальнейшем обеспечили подъем промышленного и сельскохозяйственного производства региона, базировалась на необходимости приоритетного развития электросетевого комплекса с учетом строго определенной последовательности регионального энергетического строительства, однако данные аспекты реализации планов электрификации не представлены в отечественной исторической литературе, посвященной реформированию энергетической отрасли. В статье отмечена существенная роль научно-технического сотрудничества ленинградских энергетиков и приборостроителей Чебоксар в решении труднейших задач в мирное время и в годы войны, рассмотрен вклад чувашских энергетиков, обеспечивших строительство и модернизацию десятков магистральных линий электропередачи, что позволило в полном объеме реализовать план электрификации страны и обеспечить энергетическую безопасность региона.

В плане ГОЭЛРО, принятом VIII Всероссийским съездом Советов в декабре 1920 г., электрификация рассматривалась как основа восстановления и дальнейшего развития народного хозяйства страны. В обосновании плана указывалось, что строительство районных станций станет «могучим стимулом для развития существующих отраслей промышленности и возникновения новых» [6. С. 482], а Приволжский экономический район в силу своего географического положения станет центром, «к которому будут тяготеть различные отрасли народного хозяйства». Создатели плана ГОЭЛРО справедливо считали, что строительство новых электростанций в Приволжском экономиче- 
ском районе послужит отправной точкой для нового этапа развития экономики «в направлении движения на восток» [6. С. 501].

Особая роль в плане была отведена сооружению гидроузлов на Волге и строительству единого электросетевого комплекса, связывающего через Поволжье крупные промышленные предприятия, расположенные в Центрально-промышленном экономическом районе и районе Урала. Планом предусматривалась электрификация предприятий различных отраслей, в том числе применение электрооборудования в портах и перевалочных пунктах на Волге, электрификация сельскохозяйственного труда в районах, расположенных на расстоянии до 20 верст от линий электропередачи.

По данным инвентаризации, проведенной в ходе разработки плана, в 1920 г. на предприятиях Приволжского экономического района использовались 4114 двигателей различных конструкций, большинство из которых находились в неудовлетворительном техническом состоянии. На 3163 предприятиях использовались теплоэлектрогенераторные установки, общая мощность которых составляла 168,64 МВт. Из этого количества в Саратовской губернии располагались 1117 предприятий с генераторным оборудованием мощностью 77,48 МВт (46\% всей установленной в районе мощности), в Самарской губернии - 1034 предприятия мощностью 51,4 МВт - 30,5\%, в Симбирской губернии - 413 предприятий мощностью 21,47 МВт (12,7\%), в Казанской губернии насчитывалось 313 предприятий мощностью 16,8 МВт (10\%). Наиболее мощные электростанции были расположены в крупных городах, их суммарная мощность составляла: в Самаре -12,6 МВт, в Казани - 11,96 МВт, в Саратове - 11,7 МВт и в Вольске -10,8 МВт [6. С. 480-481].

В целях электрификации существующих промышленных предприятий первая редакция плана ГОЭЛРО предусматривала увеличение мощности электростанций на 132 МВт и доведение суммарной генераторной мощности электростанций региона до 300 МВт. При этом для решения локальной задачи по организации электрификации кустарных производств планом предусматривалось выделить мощность порядка 38,9 МВт [6. С. 484].

Ввиду острого дефицита мощного энергетического оборудования первоочередной задачей стало строительство местных электростанций малой мощности, одновременно осуществлялось строительство линий электропередачи и технологические мероприятия по параллельной работе электростанций для обеспечения их максимальной загрузки.

Необходимо отметить, что в 1920 г. большинство действующих электростанций региона еще находились в частной собственности, мощность «электрических станций общественного пользования» составляла всего 8,5\% от мощности всех установок района [6. С. 505].

В первый год реализации плана усилиями губернских электроотделов был построен ряд местных электростанций, электрифицированы десятки населенных пунктов. Так, в Саратовской губернии были электрифицированы 11 сел и завершено строительство первого блока центральной станции в городе Вольске, в Симбирской губернии были электрифицированы 6 уездных городов и 9 сел. В первой половине 1921 г. в четырех городах Татарской АССР действовали электростанции, которые обеспечивали электроснабжение школ и государственных учреждений [8. С. 447-453].

Централизованное электроосвещение улиц и части учреждений Чебоксар (в количестве 100 ламп) было организовано еще в 1918 г. на основе реквизированной электростанции купца Ефремова, установленной на лесопиль- 
ном заводе [10]. 23 марта 1921 г. в Чебоксарах был введен в эксплуатацию первый из четырех блоков центральной электрической станции, которая обеспечивала электроэнергией государственный театр, городские бани и некоторые советские учреждения [8. С. 447].

В условиях дефицита нового отечественного оборудования строительство электростанций планировалось избирательно. Например, центральная электростанция в Самаре имела значительную установленную мощность на уровне 4 МВт, и по этой причине строительство местных электростанций в Самарской губернии планом ГОЭЛРО не предусматривалось. В феврале 1921 г. крестьяне села Павловка Бузулукского уезда, не дожидаясь помощи со стороны советской власти, сами выбрали комиссию по электроснабжению своей деревни [8. С. 445].

В тех населенных пунктах, где электрификация не планировалась, сбор средств для закупки генераторов и электрооборудования, а также для выполнения строительно-монтажных работ осуществлялся разнообразными способами. Так, в селе Большие Кошеля Батыревского уезда Чувашской автономной области 250 крестьянских дворов провели сбор средств для закупки генератора мощностью 6 кВт с целью электрификации мельницы [8. С. 459].

В Симбирской губернии на XIII съезде Советов Ардатовского уезда в декабре 1922 г. после обсуждения вопроса об электрификации уезда новому уездному исполкому было поручено самостоятельно разработать схему электроснабжения уезда, а средства для постройки станции и линий электропередачи изыскать «путем подворного обложения населения и торгово-промышленных предприятий, в добровольном порядке, устройства спектаклей и прочее» [8. С. 455-456].

Для осуществления электрификации Поволжья в условиях наступающего голода все чаще применялись методы, основанные на реквизиции материальных ценностей. Так, по инициативе Казанского областного комитета РКП(б) в рамках реализации плана в Татарской республике началась принудительная конфискация электротехнического оборудования. На Всетатарском съезде работников народного хозяйства, состоявшемся 25 января 1921 г., была принята резолюция об изъятии из частной собственности электрогенераторов, двигателей, электрооборудования, проводов и арматуры всех видов. Одновременно было принято решение о «взятии на учет всех специалистов в области электротехники» и установлении для них запрета на работу не по своей специальности. Сокрытие информации о своей квалификации и укрывательство инвентаря «должно рассматриваться как неисполнение боевого приказа и караться по всей строгости революционных законов» [5].

Практика конфискаций всех видов техники началась в первый год советской власти, однако после принятия плана ГОЭЛРО она приобрела повсеместный характер. Строительство местных электростанций явилось первым шагом на долгом пути электрификации Приволжского экономического района. Электричество, как и хлеб, добывалось с помощью реквизиции.

Реализация государственного плана электрификации началась в условиях отсутствия в стране отечественной машиностроительной базы. По этой причине Г.М. Кржижановский - один из создателей плана ГОЭЛРО - считал, что строительство крупных энергетических объектов во всех восьми экономических районах, рассмотренных в плане, должно быть обеспечено поставками импортного энергетического оборудования. Эти экономические идеи поддерживал и развивал Л.Д. Троцкий. Обосновывая необходимость углубления торговых связей, 
в октябре 1926 г. он писал: «...Существеннейшей чертой нашего хозяйственного роста является как раз то, что мы выходим из замкнутого государственнохозяйственного существования и вступаем во все более глубокие связи с европейским и мировым рынком. Думать, что правильное политическое маневрирование освобождает нас от мировых политических зависимостей, - значит впадать в ужасающую национальную ограниченность» [4. С. 325].

Л.Д.Троцкий, Г.М. Кржижановский, как и другие ведущие экономисты страны, лучше всех понимали, что надежды на реализацию плана электрификации страны в условиях экономической изоляции и отсутствия квалифицированных кадров были утопичными. Президиум ВСНХ, всегда учитывавший мнение И.В. Сталина, раскритиковал данную позицию. Вместе с тем организовать в кратчайшие сроки импортозамещающее машиностроительное производство при отсутствии социально-экономических ресурсов, даже в условиях жестко централизованной власти, не представлялось возможным.

В целях реализации следующих этапов по электрификации промышленности, в том числе связанных со строительством крупных гидроузлов на Волге, советское руководство было вынуждено принять решение о закупке энергетического оборудования за рубежом. Изучение импортного оборудования большой мощности позволило повысить качество проектирования и строительства гидроэнергетических объектов, а затем на базе ленинградских энергомашиностроительных заводов перейти к созданию технологически более совершенных отечественных аналогов закупаемого за рубежом оборудования.

План ГОЭЛРО по ряду показателей был выполнен в 1931 г., но итоги его реализации были подведены только в январе 1935 г. Плановые показатели в полном объеме фактически были достигнуты только в конце второй пятилетки в 1937 г.

Главными итогами реализации этого плана явились строительство районных электростанций и создание условий для строительства мощных энергосистем в промышленных районах страны, в том числе для сооружения Волжского каскада гидроэлектростанций.

В рамках развития плана ГОЭЛРО в мае 1931 г. началась разработка Генерального плана электрификации СССР. В его преамбуле указывалось на преемственность двух планов электрификации: «Крупные районные станции должны явиться ядром тех новых энергопромышленных комбинатов, которые теперь сооружаются по всей стране» [3. С. 27].

Особое внимание в Генеральном плане было отведено электрификации Нижегородского и Нижне-Волжского краев и сооружению здесь гидроузлов, которые в дальнейшем составили основу Волжского каскада. Вместе с тем ключевым моментом в создании единой энергосистемы страны стало решение о координации строительства мощных гидроэлектростанций и межрегиональных магистральных линий электропередачи.

Электрификация Нижегородского края предусматривала возведение гидроэлектростанции в районе Чебоксар и связанных с ней магистральных электросетей, пересекающих территорию Чувашской АССР. Предполагалось, что эти объекты, с одной стороны, обеспечат «мощный толчок к индустриализации района по линии энергоемких производств (электростали, ферросплавов, электрохимии)», с другой стороны, образуют основное звено в едином электросетевом комплексе, связывающем через Поволжье крупные промышленные центры от западных границ страны до Западной Сибири [3. С. 584]. Таким образом, эта задача, сорормулированная ранее в плане ГОЭЛРО, обрела новое звучание. 
Проектно-изыскательские работы по гидроузлу в Чебоксарском и прилегающих к нему районах начались в марте 1932 г. силами треста «Гидроэлектрострой» Энергоцентра ВСНX СССР [2. С. 141]. Общая стоимость изыскательских работ составила 8 млн 200 тыс. руб. [13]. Схема «Большая Волга» была утверждена комиссией Госплана СССР в 1936 г., однако разработка проектной документации продолжалась до 1970-х гг. [2. С. 154].

Решение о строительстве высоковольтных магистралей было детально проработано и предусматривало строительство к 1937 г. кольцевой линии электропередачи напряжением 220 кВ (с дальнейшим переходом на напряжение 400 кВ и 500 кВ) длиной 1275 км, связывающей станции основных энергетических узлов и проходящей через Чебоксарскую ГЭС. Далее предполагалось строительство трех примыкающих кольцевых линий напряжением 110 кВ, в том числе Чувашского кольца, охватывающего районы Чувашской сланцевой станции и Чебоксарской ГЭС. Южная часть большого кольца, проходящая через Чебоксары, позволяла связать промышленные районы Урала с западными промышленными центрами страны [3. С. 658-659].

Одним из основных источников трудовых ресурсов, использованных на строительстве гидроэлектростанций на Волге, являлся принудительный труд заключенных. При этом использование их на работах по эксплуатационному обслуживанию энергооборудования было запрещено распоряжением СНК СССР № 16643-рс 6 сентября 1942 г. [15]. Задачи по реконструкции и ремонту электростанций и электросетевых хозяйств также решались силами специалистов региональных энергетических управлений. Особенность принудительного труда заключалась в возможности высоких социальных и экономических потерь, недопустимых при использовании наемного труда с привлечением высококвалифицированных специалистов. Строительство гидроузлов на Средней Волге характеризовалось «крайне низким уровнем механизации работ и использования завезенных строймеханизмов, вследствие чего получен огромный перерасход рабочей силы» [14]. Согласно докладной записке прокурора Волгостроя-Волголага НКВД СССР, в Волжском ИТЛ в 1941 г. находились до 95 тыс. человек [20].

Набиравшая темпы реализация генерального плана была частично приостановлена с началом Великой Отечественной войны. По нашему мнению, одной из основных причин замедления гидростроительства явилось незавершенное строительство кольцевых сетевых магистралей. Строительство сверхмощных гидроэлектростанций на Волге теряло смысл в условиях отсутствия единой энергетической системы страны, связывающей регионы магистральными взаиморезервируемыми линиями электропередачи. Однако, согласно официальной версии, строительство Куйбышевского гидроузла было законсервировано на 3-4 года «в связи с отсутствием свободной рабочей силы», - так было указано в постановлении СНК СССР и ЦК ВКП(б) № 1780-741/с от 24 сентября 1940 г. [17]. Согласно другой версии, строительство было остановлено в связи с принципиальными ошибками, допущенными в ходе подготовки проектной документации, - об этом говорилось в письме профессора А. Сенкова на имя В.М. Молотова в июне 1940 г., которое было передано Л.П. Берии [19]. По нашему мнению, данный вопрос является дискуссионным, в частности с учетом того, что причиной замедления строительства могла стать нехватка или нецелевое использование материальных и денежных средств, - как на строительстве гидроузла, так и на монтаже многокилометровых сетевых магистралей. При начальной сметной стоимости Куйбышевского гидроузла в сумме около 8 млрд руб. фактическое финансирование работ составило более 10 млрд руб. [16]. Управление строительства Куйбышевского гидроузла и Управление Са- 
марлага 11 октября 1940 г. были расформированы в рабочем порядке, а тысячи заключенных переброшены на строительство авиационных заводов, энергетических и жилых объектов [18].

Находясь в тылу фрронта, районные энергосистемы наращивали установленную мощность и объемы производства электроэнергии с целью круглосуточного энергоснабжения оборонных предприятий. Так, электростанции Горэнерго за годы войны к 1945 г. увеличили выработку электроэнергии с 1276 до 1397 млн кВт.ч в год, станции Саратовэнерго - с 202 до 317 млн кВт.ч, Казэнерго - с 271 до 443 млн кВт.ч, станции Куйбышевэнерго увеличили выработку электроэнергии в 3,8 раза с 201 до 759 млн кВт.ч [11]. Мощность электрогенераторов на территории Чувашской АССР за годы войны увеличилась с 14,2 МВт до 22,7 МВт [12].

В середине 1950-х гг. после десятилетнего восстановительного периода была введена в эксплуатацию линия электропередачи напряжением 400 кВ от Куйбышева до Москвы. На этой основе произошло объединение энергосистемы Средней Волги и энергосистемы Центра. Это событие положило начало созданию единой энергетической системы СССР. Дальнейшее строительство двух линий напряжением 500 кВ Чебоксарская ГЭС - Помары (77 км) и Чебоксарская ГЭС - Нижегородская ГЭС (254 км), завершенное в 1978 г., позволило осуществить параллельную работу энергосистем Центра, Нижней и Средней Волги и Урала.

Реализация масштабного проекта «Большая Волга», начатая в 1932 г. с сооружения Ярославского гидроузла, завершилась после полного ввода в эксплуатацию Чебоксарского гидроузла в 1989 г. Ввод в строй Чебоксарской ГЭС состоялся раньше - в 1980 г. За полвека упорного труда с привлечением специалистов из других регионов страны были сооружены основные гидроузлы объединенной энергетической системы Средней Волги: в 1955 г. сдана в эксплуатацию Нижегородская (Горьковская) ГЭС, в 1955 г. - Жигулёвская (Куйбышевская) ГЭС, в 1958 г. - Волжская (Сталинградская) ГЭС, в 1967 г. - Саратовская ГЭС.

При сооружении Куйбышевской и Сталинградской ГЭС, а позднее и на строительстве других волжских гидроузлов использовались гидроагрегаты, выпущенные в начале 1950-х гг. на ленинградских машиностроительных заводах. Вопросы, связанные с определением мощности машин, их габаритов и технологических характеристик решались научно-техническим советом ленинградского завода «Электросила» с привлечением ведущих энергетиков Ленинграда [1. С. 200].

Так, например, специалисты завода сумели построить для Куйбышевской ГЭС мощный генератор для обеспечения надежной работы рабочего колеса поворотно-лопастных турбин массой 450 т и массой вала более 50 т [7].

В 1942 г. на территории Чебоксарского электроаппаратного завода был размещен эвакуированный из Ленинграда завод «Электрик», находящийся в ведомстве Наркомата электротехнической промышленности СССР. В начале 1950-х гг. Чебоксарский завод поставлял в Ленинград низковольтное электрощитовое оборудование и аппаратуру релейной защиты и автоматики, что позволило запустить ленинградское метро с опережением графика в ноябре 1955 г.

После ввода в эксплуатацию первых ГЭС энергосистемы Средней Волги распоряжением Чувашского совнархоза № 21 от 26 сентября 1957 г. было создано Чувашское энергетическое управление. Оперативное управление процессом производства, преобразования и распределения электроэнергии на территории Чувашии и прилегающих к ней районов осуществляло Чувашское региональное диспетчерское управление. Республика являлась энерго- 
достаточным регионом. Объемы выработки электроэнергии на ее территории превышали объемы потребления, которые с момента создания энергоуправления к настоящему времени выросли более чем в 40 раз. В настоящее время Чувашская ГЭС производит 2,1 млрд кВт·ч электроэнергии в год, ее установленная мощность составляет 1370 МВт.

После реорганизации, проведенной в рамках оптимизации структуры оперативно-диспетчерского управления, функции управления электроэнергетическим режимом на территории Чувашской Республики 16 сентября 2014 г. были переданы Нижегородскому региональному диспетчерскому управлению. В результате оптимизации межрегиональных перетоков энергии, несмотря на избыток располагаемой электрической мощности на территории Чувашии на уровне 762 МВт в 2019 г., в настоящее время республика является энергодефицитным регионом: в 2019 г. потребление электроэнергии в республике составило 5,11 млрд кВт.ч, объем выработки составил всего 4,13 млрд кВт.ч в год [9. С. 4].

В период до 2025 г. энергосистема Чувашской Республики останется избыточной по мощности и дефицитной по электрической энергии [9. С. 5]. Обладая резервом электрической мощности, регион не вправе использовать эту мощность в собственных экономических целях. Согласно Схеме и программе перспективного развития электроэнергетики Чувашской Республики на 2021-2025 гг., утвержденным распоряжением Главы Чувашской Республики № 205-рг от 30 апреля 2020 г., в ближайшие пять лет энергообеспеченность региона в плановом порядке будет повышаться, дополнительный переток энергии из других энергосистем предполагается снизить на 35\%: с 978 млн кВт.ч до 640 млн кВт.ч в год [9. С. 4].

В настоящее время энергетики Чувашии обеспечивают надежную эксплуатацию Чебоксарской ГЭС и электросетевого комплекса, состоящего из 5,3 тыс. трансформаторных подстанций общей мощностью более 1000 МВт и линий электропередачи общей протяженностью более 25 тыс. км.

Вопрос завершения строительства Чебоксарского гидроузла с подъёмом водохранилища до проектной отметки 68 м с обустройством зоны затопления (что позволит вывести станцию на проектную мощность 1404 МВт) вызывает разногласия между затрагиваемыми регионами и требует расширения научнотехнического и экономического сотрудничества всех заинтересованных сторон.

Залогом дальнейших успехов в развитии энергетической системы Чувашской Республики - центрального звена единой энергетической системы России - является многолетний самоотверженный труд чувашских энергетиков и строителей, достойно преодолевших тяжелые исторические испытания, выпавшие на долю народа Чувашии за последние сто лет.

\section{Литература}

1. Арсенал электрифрикации: Краткий очерк истории ленинградского завода «Электросила» имени С.М. Кирова. Л.: Лениздат. 1960. 268 с.

2. Бурдин Е.А. Гидростроительство в России: от самарского Волгостроя к Большой Волге (1930-1980 гг.). Ульяновск: УлГПУ, 2010. 222 с.

3. Генеральный план электрификации СССР / Госплан СССР; под ред. Г.И. Ломова. Т. 8, ч. 1: Сводный план электрификации. М.; Л.: Гос. соц.-экон. изд-во, 1932. 856 с.

4. Дэй Р. Лев Троцкий и политика экономической изоляции. М.: Дело, 2013. 472 с.

5. Известия. 1921. № 21(322), 30 янв.

6. План электрификации РСФСР. М.: Гос. тех. изд-во, 1920. 660 с.

7. Правда. 1953. 30 марта.

8. Развитие электрификации советской страны. 1921-1925 гг. Сб. документов и материалов / ред. А.И. Гладков. М.: Госполитиздат, 1956. 703 с. 
9. Схема и программа перспективного развития электроэнергетики Чувашской Республики на 2021-2025 годы: распоряжение Главы Чувашской Республики № 205-рг от 30.04.2020 г. [Электронный ресурc]. URL: http://fs01.cap.ru/www20/gov/laws/2020/4/ 30/8f2c38f5-7d23-41a6-a283-7a79c55ad766/205-rg-3004.

10. Энергия - наша работа [Электронный ресурс] // Советская Чувашия: сайт CMИ. URL: http://sovch.chuvashia.com/?p=67345 (дата обращения: 02.10.2020).

11. Российский государственный архив экономики (далее - РГАЭ). Ф. 1562. Оп. 33. Д. 542, Л. 32, 33, 36.

12. РГАЭ. Ф. 1562. Оп. 329. Д. 1594 Л. 58.

13. РГАЭ. Ф. 4372. Оп. 28. Д. 456. Л. 11-12.

14. Государственный архив Российской Федерации (далее - ГАРФ). Ф. Р-5446. Оп. 24а. Д. 6. Л. 20.

15. ГА РФ. Ф. Р-5446. Оп. 43а. Д. 2321. Л. 73.

16. ГА РФ. Ф. Р-5446. Оп. 1. Д. 142. Л. 8.

17. ГА РФ. Ф. Р-5446. Оп. 1. Д. 518. Л. 212-213.

18. ГА РФ. Ф. Р-5446. Оп. 24а. Д. 6. Л. 21.

19. ГА РФ. Ф. Р-5446. Оп. 24а. Д. 6. Л. 97-99.

20. ГА РФ. Ф. Р-8131. Оп. 37. Д. 809. Л. 224-229.

АВДАНИН ВЛАДИМИР ВЛАДИМИРОВИЧ - аспирант кафедры государственного и муниципального управления, Северо-Западный институт управления Российской академии народного хозяйства и государственной службы при Президенте Российской Федерации, Россия, Санкт-Петербург (avdanin@mail.ru; ORCID: https://orcid.org/0000-0003-0703-7167).

\section{Vladimir V. AVDANIN \\ 100 YEARS OF ELECTRIFICATION: HISTORICAL EXPERIENCE AND MODERN CHALLENGES}

Key words: GOELRO plan, General plan of electrification of the USSR, power system of the Middle Volga, Cheboksary HPP, Chuvashia.

Basing on the principles of historicism and objective analysis the article examines the features and problems of implementing two state electrification plans: GOELRO plan adopted 100 years ago, under which the construction of local power plants in the Middle Volga region began, and the General Plan for the USSR Electrification, approved in 1932, which laid down the main solutions to radically redevelop the industry and agriculture of the region on the basis of using the sources of hydroelectric power, constructed on the Volga. In this regard, the historical and comparative method made it possible to highlight the main stages in creation and development of the power system of the Chuvash Republic, which since the mid 1950s has acted as a central a link in the country's unified electric power system. The idea of creating energy hubs of the Volga Cascade, which in the years that followed provided the rise of industrial and agricultural production of the region, was based on the need for the priority development of the integrated power grid taking into account a strictly defined sequence of regional power plant construction, however, these aspects of implementing the electrification plans are not exampled in the domestic historical literature devoted to the reform of the energy industry. The article notes the pivotal role of scientific and technical cooperation between Leningrad and Cheboksary power engineers and instrument makers in solving the most complicated tasks in times of peace and during the war, it considers the contribution of Chuvash power engineers, who provided the construction and modernization of dozens of trunk transmission lines, which made it possible to fully implement the country's electrification plan and to ensure energy security of the region. 


\section{References}

1. Arsenal elektrifikatsii: Kratkiy ocherk istorii leningradskogo zavoda «Elektrosila» imeni S.M. Kirova [Arsenal of electrification: a short story of the Leningrad plant "Electrosila" named S.M. Kirov"]. Leningrad, Lenizdat Publ., 1960, 268 p.

2. Burdin E.A. Gidrostroitel'stvo v Rossii: ot samarskogo Volgostroya k Bol'shoy Volge (1930-1980 gg). [Hydroconstraction in Russia: from Samara Volgostroi to the Big Volga (1930-1980s)]. Ul'yanovsk, Ulyanovsk State Pedagogical Institute Publ., 2010, 222 p.

3. Lomov G.I., ed. General'nyy plan elektrifikatsii SSSR [General plan for electrification of the USSR]. Moscow, Leningrad, 1932, vol. 8, part. 1, 856 p.

4. Dey R. Lev Trotskiy i politika ekonomicheskoy izolyatsii [Leon Trotsky and economic isolation policy]. Moscow, Delo Publ., 2013, 472 p.

5. Izvestiya, 1921, no. 21(322), Jan. 30.

6. Plan elektrifikatsii RSFSR [Plan for electrification of the RSFSR]. Moscow, 1920, $660 \mathrm{p}$.

7. Pravda, 1953, March 30.

8. Gladkov A.l., ed. Razvitiye elektrifikatsii sovetskoy strany. 1921-1925 gg. Sb. dokumentov i materialov [Development of the electrification of the Soviet country. 19211925s. Collection of documents and materials]. Moscow, Gospolitizdat Publ., 1956, 703 p.

9. Skhema i programma perspektivnogo razvitiya elektroenergetiki Chuvashskoy Respubliki na 2021-2025 gody [Sheme and program for the prospective development of the electric power industry of the Chuvash republic for 2021-2025s]. Order of the head or the Chuvash republic № 205-rg, 30 april 2020. Available at: http://fs01.cap.ru/www20/gov/ laws/2020/4/30/8f2c38f5-7d23-41a6-a283-7a79c55ad766/205-rg-3004.

10. Energiya - nasha rabota [Energy is our job]. Available at: http://sovch.chuvashia.com/?p=67345Sovetskaya.

11. Gosudarstvennyi arkhiv Rossiiskoi Federatsii. F. R-5446. Op. 24a. D. 6. L. 20 [Russian State Archives of Economics. Archive 1562. Anagraph 33. Document 542. P. 32, 33, 36].

12. Gosudarstvennyi arkhiv Rossiiskoi Federatsii. F. 1562. Op. 329. D. 1594. L. 58 [Russian State Archives of Economics. Archive 1562. Anagraph 329. Document 1594. P. 58].

13. Gosudarstvennyi arkhiv Rossiiskoi Federatsii. F. 4372. Op. 28. D. 456. L. 11-12 [Russian State Archives of Economics. Archive 4372. Anagraph 28. Document 456. P. 11-12].

14. Gosudarstvennyi arkhiv Rossiiskoi Federatsii. F.R-5446. Op. 24a. D. 6. L. 20 [State Archive of Russian Federation. Archive R-5446. Anagraph 24a. Document 6. P. 20].

15. Gosudarstvennyi arkhiv Rossiiskoi Federatsii.F. R-5446. Op. 43a. D. 2321. L. 73 [State Archive of Russian Federation. Archive R-5446. Anagraph 43a. Document 2321. P. 73].

16. Gosudarstvennyi arkhiv Rossiiskoi Federatsii. F. R-5446. Op. 1. D. 142. L. 8 [State Archive of Russian Federation. Archive R-5446. Anagraph 1. Document 142. P. 8].

17. Gosudarstvennyi arkhiv Rossiiskoi Federatsii. F. R-5446. Op. 1. D. 518. L. 212-213 [State Archive of Russian Federation. Archive R-5446. Anagraph 1. Document 518. P. 212-213].

18. Gosudarstvennyi arkhiv Rossiiskoi Federatsii. F. R-5446. Op. 24a. D. 6. L. 21 [State Archive of Russian Federation. Archive R-5446. Anagraph 24a. Document 6. P. 21].

19. Gosudarstvennyi arkhiv Rossiiskoi Federatsii. F. R-5446. Op. 24a. D. 6. L. 97-99 [State Archive of Russian Federation. Archive R-5446. Anagraph 24a. Document 6. P. 97-99].

20. Gosudarstvennyi arkhiv Rossiiskoi Federatsii. F. R-8131. Op. 37. D. 809. L. 224229 [State Archive of Russian Federation. Archive R-8131. Anagraph 37. Document 809. P. 224-229].

VLADIMIR V. AVDANIN - Post-Graduate Student, Department of State and Municipal Administration, North-West Institute of Management, Russian Academy of National Economy and Public Administration under the President of the Russian Federation, Russia, St. Petersburg (avdanin@mail.ru; ORCID: https://orcid.org/0000-0003-0703-7167).

Формат цитирования: Авданин В.В. Сто лет электрификации: исторический опыт и современные вызовы // Исторический поиск. - 2020. - Т. 1, № 3. - C. 5-13. DOI: 10.47026/2712-9454-2020-1-3-5-13. 